\title{
Ocular blood flow in patients with obstructive sleep apnea syndrome (OSAS)
}

\author{
Sarper Karakucuk • Sertan Goktas • Murat Aksu • \\ Nuri Erdogan • Sevda Demirci • Ayse Oner • \\ Hatice Arda $\cdot$ Koray Gumus
}

Received: 15 January 2007 / Revised: 19 June 2007 / Accepted: 1 July 2007 / Published online: 4 August 2007

(C) Springer-Verlag 2007

\begin{abstract}
Background Sleep-related disorders are among the important risk factors for neurovascular diseases. Obstructive sleep apnea syndrome (OSAS) is characterized by snoring, excessive daytime sleepiness, and insomnia. Our aim was to investigate the presence of glaucoma in patients with OSAS and to reveal vascular pathology related to the pathogenesis of glaucoma in those patients.

Patients and methods The study included 31 patients with OSAS and 25 control subjects. Orbital Doppler ultrasonography was used to determine the resistivity index (RI) in the ophthalmic artery and central retinal artery. All patients and controls underwent perimetric examination.

Results The prevalence of glaucoma in the group of patients with OSAS was $12.9 \%$ (4/31); all of these 4 patients with glaucoma were in the "severe" OSAS group. No statistically significant difference was found between ophthalmic artery resistivity index (OARI), central retinal artery resistivity index (CRARI), and intraocular pressure (IOP) between patients and controls $(p>0.05)$. There was a positive correlation between OARI and mean defect (MD),
\end{abstract}

S. Karakucuk $(\bowtie) \cdot$ S. Goktas $\cdot$ A. Oner $\cdot$ H. Arda $\cdot$ K. Gumus Department of Ophthalmology, Faculty of Medicine, Erciyes University,

Melikgazi, Kayseri, Turkey 38039

e-mail: sarperkarakucuk@gmail.com

M. Aksu $\cdot$ S. Demirci

Department of Neurology, Faculty of Medicine,

Erciyes University,

Melikgazi, Kayseri, Turkey

N. Erdogan

Department of Radiology, Faculty of Medicine,

Erciyes University,

Melikgazi, Kayseri, Turkey
CRARI and MD, and CRARI and loss variance (LV) values $(p<0.05)$. There was also a positive correlation between IOP and the apnea-hypopnea index (AHI) $(p=0.001)$.

Conclusions In patients with OSAS, a high prevalence was found and it is interesting to note that all of the four glaucoma patients were in the severe OSAS group. The positive correlation observed between IOP and AHI suggests that increased IOP values may reflect the severity of OSAS. The positive correlation between OARI and MD and also between CRARI and MD as well as LV suggests that visual field defects may be due to optic nerve perfusion defects and these field defects also increase as the RI increases.

Keywords Obstructive sleep apnea syndrome - Glaucoma . Ocular blood flow - Apnea-hypopnea index .

Polysomnography

Obstructive sleep apnea syndrome (OSAS) is characterized by snoring, excessive daytime sleepiness, and insomnia. Epidemiological studies revealed a prevalence between 2 and $20 \%$. Among the risk factors, obesity, male gender, upper respiratory tract abnormality, consumption of alcohol, snoring, and thick neck are worth mentioning $[5,11$, 12].

In previous studies, retinal vascular tortuosity and congestion [7], floppy eyelid syndrome [3, 18, 22, 27], keratoconus [22], papilledema, and optic neuropathy [2, $14,20]$ have been described in patients with OSAS. It has been stressed that OSAS may be a predisposing condition for anterior optic neuropathy [14]. In a study, Mojon et al., investigating 69 patients with OSAS, found the incidence of glaucoma to be $7.2 \%$ [21]. Onen et al. found a high incidence (14.6-47.6\%) of primary open-angle glaucoma 
(POAG) in patients with sleep-disordered breathing [24]. Similarly, in another study by Mojon et al., the prevalence of low-tension glaucoma (LTG) in patients with OSAS was found to be $50 \%$ [23]. Recently, in a study from Turkey, it was stated that OSAS is correlated with a proportional decrease in retinal nerve fiber layer (NFL) [15].

The study's aim was to investigate the ocular blood flow in patients with OSAS since pathological ocular blood flow has been suggested as a major mechanism in the etiology of glaucoma and also to detect the glaucoma prevalence in the study group.

\section{Patients and methods}

Patients were recruited from those who were referred for suspected OSAS to the "Sleep Unit" of the Neurology Clinic (Erciyes University Faculty of Medicine, Kayseri, Turkey) between December 2003 and July 2004. These were consecutively all patients referred to the Sleep Unit during the 7-month period. A total of 42 patients were evaluated during this period. Among these, 31 patients fulfilled the inclusion criteria. The remaining 11 patients were excluded from the study because they had at least one of the exclusion criteria (such as those who had previous eye surgery or laser treatment, who had any anterior or posterior segment disease or a history of ocular trauma, those with secondary glaucoma, history of chronic steroid use, history of shock, and diabetes mellitus).

The study included 31 patients with OSAS and 25 healthy controls. Diagnosis of OSAS was made by the Sleep Unit of the Neurology Clinic.

Atherosclerotic risk factors likely to affect ocular blood flow such as hypertension, cigarette smoking, and high blood cholesterol level were investigated in all subjects; since it was impossible to completely eliminate these factors in both groups, the distribution of these risk factors was investigated and it was found to be similar between the groups (chi-square: $1.97 ; p=0.16$ ).

Criteria for the diagnosis of POAG were as follows (all four of the criteria listed had to be present for inclusion in the study):

1. A cup to disc ratio (c/d) over 0.5 or difference of $\mathrm{c} / \mathrm{d}$ between two eyes $>0.2$ with thinning of the neuroretinal rim; a careful search was made to detect the presence of any disc hemorrhages to strongly support the diagnosis. The $\mathrm{c} / \mathrm{d}$ ratio and the optic disc evaluation were derived with a +90 diopter aspherical Volk lens by two independent examiners who were masked to the condition of the patient.

2. Any of the detected visual field defects such as localized defects, paracentral scotoma, Bjerrum scoto- ma, nasal step, temporal sector defect, and diffuse defect which cannot be explained by any neurologic or fundus lesion.

3. Open iridocorneal angle.

4. An intraocular pressure (IOP) $>21 \mathrm{mmHg}$ without treatment.

Diagnosis of normotensive glaucoma was made with criteria similar to those stated for POAG except for the fact that IOP was $<21 \mathrm{mmHg}$ without treatment.

The control group consisted of 25 age- and sex-matched healthy subjects who were recruited from those attending the eye clinic for conditions such as refractive errors, etc. Control subjects had to meet all of the following ophthalmological criteria for inclusion in the study:

1. No IOP elevation over $21 \mathrm{mmHg}$

2. No evidence of glaucomatous optic nerve appearance (no disc hemorrhages) and a c/d ratio less than 0.5

3. Normal anterior chamber angle on slit lamp and gonioscopic examination

4. Normal visual field test results

5. No previous history of antiglaucomatous drug usage, ocular trauma, ocular surgery, or laser therapy

Patients underwent orbital color Doppler ultrasonography (Toshiba Power Vision 6000, Osaka, Japan) at the Radiology Unit of the University. An $11-\mathrm{MHz}$ linear surface probe was used and the measurements were performed between 12:00 a.m. and 13:00 p.m. The patient was supine; eyes were closed and aimed at the ceiling under the closed eyelids. Systolic blood velocity (PSV) and enddiastolic blood velocity (EDV) were calculated in the ophthalmic artery and central retinal artery; resistivity index (RI) was calculated for the central retinal artery (CRARI) and ophthalmic artery (OARI; RI=PSV-EDV/PSV).

Polysomnography was performed at the Sleep Research Unit of the University; it was constituted by two EEG channels, two EOG channels, one EMG channel recording from the submental muscle, one nasal current channel, one thoracic motion channel, one abdominal motion channel, one oximeter channel, a microphone, two leg movement channels from the right and left anterior tibialis muscles, and video recordings made between 2300 and 0700 hours. The parameter used was the apnea-hypopnea index (AHI). Diagnosis of OSAS was made when the AHI was over 5. When the AHI was between 5 and 15, OSAS was regarded as "mild," between 16 and 30 as "moderate," and when it was over 30 , it was regarded as "severe."

All the subjects in the study underwent a complete ophthalmological examination including visual acuity, slit lamp biomicroscopy, IOP measurement, gonioscopy, and fundus examination. Perimetric examination was made with the Octopus $500 \mathrm{EZ}$ perimeter (Interzeag AG, Schlieren, 
Switzerland); stimulus size: white, III, full threshold strategy was used. Only phases 1 and phase 3 of the G1 program were used. The Octopus perimeter has a prior education (preparation) program for possibly naive patients, which was used for all patients who were naive to the examination.

A factor based on the number of false-positive and falsenegative replies to the stimuli, and their ratio $(<13 \%)$, was used to determine reliability. Unreliable results were retested on another day.

Disc analysis was made with the Heidelberg Retinal Tomograph II (Heidelberg Engineering GmbH 2001, software version 3.0, Heidelberg, Germany). Mean nerve fiber layer thickness, rim area, rim volume, and linear c/d ratio were noted.

All statistical analyses were carried out using statistical software (SPSS, version 10.0 for Windows, SPSS Inc., Chicago, IL, USA). Differences were considered significant at $p<0.05$. Student's $t$-test was used for intergroup analysis; chi-square, and Kruskal-Wallis, and Mann-Whitney U tests for nonparametric tests; analysis of variance (ANOVA) was used for the correlation analysis.

The study was conducted in accordance with the Declaration of Helsinki and was approved by an Institutional Ethics Committee.

\section{Results}

This study included 31 patients ( 7 female, 24 male) and 25 controls (7 female, 18 male). There was no significant difference among the groups in terms of sex distribution (Yates corrected chi-square $=0.02 ; p=0.88$ ). While the mean age of the patient group was $52.07 \pm 9.35$ years, it was $50.44 \pm 6.38$ years in the control group; there was no statistically significant difference between age distributions among the groups ( $p=0.13$, unpaired Student's $t$-test). There was no statistically significant difference between the two groups with respect to the distribution of arteriosclerotic risk factors and hypertension (Yates corrected chi-square $=1.97 ; p=0.16$ ).

The prevalence of glaucoma was 4 of 31 OSAS patients $(12.9 \%)$. In two of these four patients, both eyes were affected. One of these patients had normotensive glaucoma and one had POAG. The other two patients had normotensive glaucoma only in one eye. The other eyes had large cupping without any visual field defect. All of these four patients belonged to the severe OSAS group (AHI $>30$ ).

There was no significant difference between mild, moderate, or severe OSAS patients in terms of OARI or CRARI values (Kruskal-Wallis test $p=0.961, p=0.774$ ).

The patient and control groups did not differ significantly in terms of CRARI and OARI or IOP $(p>0.05$; Table 1$)$.

There was a statistically significant difference between median IOP values of mild $(10.5 \mathrm{mmHg}$; range: 9$18 \mathrm{mmHg}$ ) and severe (14.5 mm Hg; range: 9-27 mmHg) OSAS patients ( $p=0.031$; Mann-Whitney $\mathrm{U}$ test).

When correlation was analyzed between variables, a statistically significant correlation was found between OARI and MD values $(r=0.339, p=0.007$, Fig. 1$)$, CRARI and MD values ( $r=0.246, p=0.05$, Fig. 2 ), CRARI and LV values $(r=0.253, p=0.048$, Fig. 3 ), and AHI and IOP values $(r=0.426, p=0.001$, Fig. 4$)$.

\section{Discussion}

This study aimed to investigate the prevalence of glaucoma in patients with OSAS and also to investigate the association of ocular blood flow with OSAS and glaucoma. In previous studies, while the prevalence of glaucoma was found to be $2 \%$ [8], no correlation was obtained between respiratory disturbance index (RDI) and IOP. However, many other studies found higher incidences and a positive correlation between IOP and RDI. For instance, Mojon et al. stated that there was a positive correlation between IOP and RDI in 114 glaucoma suspects [21]. In our study, similar to Mojon et al.'s study, there was a significantly positive correlation between IOP and AHI $(r=0.426, p=$ $0.001)$. In another study by Robert et al., which was carried out with 69 patients with OSAS, prevalence was found to be $7.2 \%$ [27]. At the same time, a strong positive correlation was found between OSAS and lid hyperlaxity [27]. In that study, incidence was $8.7 \%$ and six patients were referred for glaucoma treatment [27]. In the study of $\mathrm{McNab}$ et al. in which 8 patients with floppy eyelid syndrome were investigated for OSAS and 20 other patients with known OSAS were examined for floppy eyelid
Table 1 Comparison of patients and controls with respect to intraocular pressure (IOP), ophthalmic artery resistivity index (OARI), and central retinal artery resistivity index (CRARI)

\begin{tabular}{lllll}
\hline Parameters & $\begin{array}{l}\text { Patient eyes } \\
(\text { mean } \pm \text { SD) }(n=62)\end{array}$ & $\begin{array}{l}\text { Control eyes } \\
(\text { mean } \pm \text { SD) }(n=50)\end{array}$ & $t$ & $p$ \\
\hline IOP $(\mathrm{mmHg})$ & $13.37 \pm 4.37$ & $14.00 \pm 4.31$ & -1.00 & 0.32 \\
OARI & $0.72 \pm 0.06$ & $0.71 \pm 0.06$ & 0.769 & 0.44 \\
CRARI & $0.69 \pm 0.06$ & $0.70 \pm 0.05$ & -0.803 & 0.42 \\
\hline
\end{tabular}




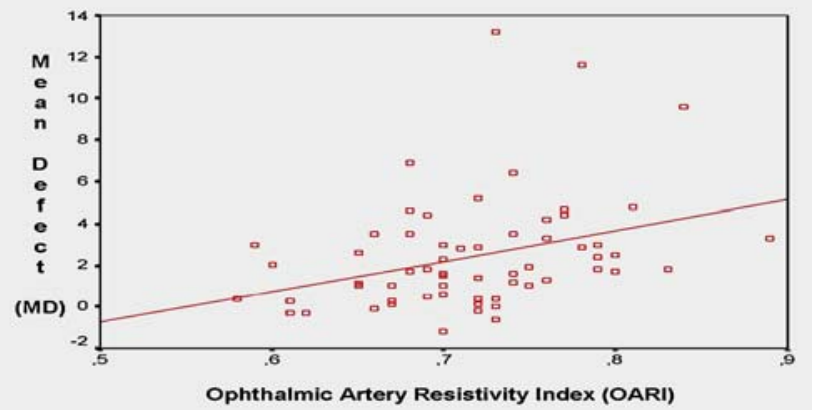

Fig. 1 The positive correlation between ophthalmic artery resistivity index (OARI) and mean defect (MD) in the patient group is statistically significant $(r=0.339, p=0.007)$

syndrome and other possibly associated ocular features, it was found that 1 of 8 patients with floppy eyelids had normotensive glaucoma [18]. Onen et al. found a high prevalence of sleep-disordered breathing (SDB) in POAG patients [24]. When only snoring was taken into consideration, the incidence of "only snoring" was $47.6 \%$, "snoring and excessive daytime sleeping" was $27.3 \%$, and "snoring, daytime sleepiness, and insomnia" was 14.6\% [24]. Marcus et al. also stressed that SDB may be a risk factor for lowtension glaucoma (LTG) [17]. Mojon et al. found that the prevalence of OSAS was $50 \%$ in LTG patients aged between 45 and 64 years and $63 \%$ in those over 64 years of age [23]. However, Girkin et al. [9] reported an odds ratio of 2.02 for OSAS patients to develop glaucoma.

Similar to most of the above-mentioned studies, the authors of the present study also found a high prevalence of glaucoma $(12.9 \%)$ in the study group of 31 patients suggesting that OSAS in conjunction with a vessel disease is an important risk factor for glaucoma.

The correlation between RDI and IOP was also investigated by Geyer et al. [8]; the authors stated that there was no statistically significant correlation [8]. On the contrary, Mojon et al. found a positive correlation between two variables [21]. We found a statistically significant

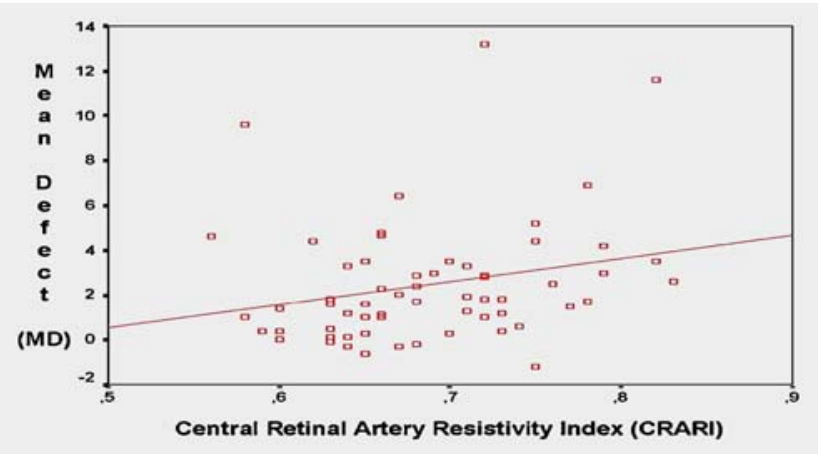

Fig. 2 The positive correlation between central retinal artery resistivity index (CRARI) and mean defect (MD) in the patient group is statistically significant $(r=0.246, p=0.05)$

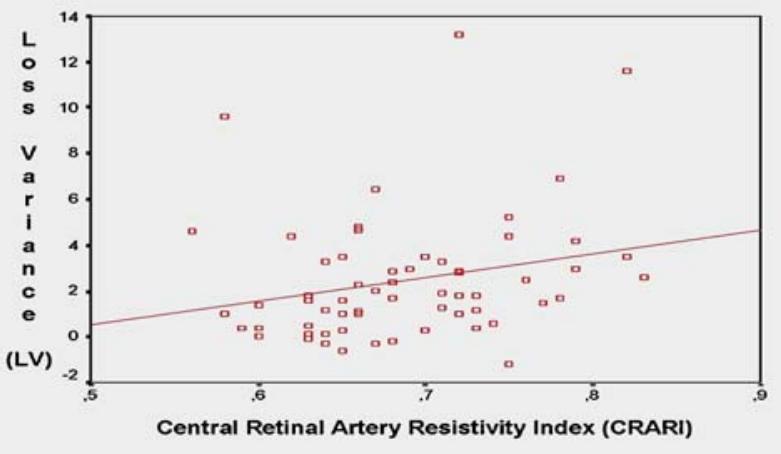

Fig. 3 The positive correlation between central retinal artery resistivity index (CRARI) and loss variance (LV) in the patient group is statistically significant $(r=0.253, p=0.048)$

difference between AHI and IOP in mild and severe OSAS patients. In our study, all four glaucomatous patients were in the severe OSAS group with an AHI $>30$. In the patient group, there was a positive correlation between OARI and MD as well as CRARI and MD, and LV. Tsang et al. also found that moderate to severe OSAS patients were associated with a higher incidence of visual field defects [29]. These results suggest that visual field defects may be caused by optic nerve perfusion insufficiency and that when RI increases, field defects also increase. However, there was no significant difference between OARI and CRARI values of patients and healthy subjects. This may suggest that the effects of OSAS on body systems are seen not only during sleep but also during daytime; pathological changes may be more clearly documented if recordings and ultrasonography can be made during the sleeping period with a suitable technique to be developed in the future. Hypoxia in OSAS is of intermittent character and the thinning may occur in the progression of the disease in such patients. Long-term follow-up of these patients in terms of NFL thickness changes over time may clarify this issue. Purvin et al. suggested that intracranial pressure increases as a result of episodic nocturnal hypoxemia and hypercap-

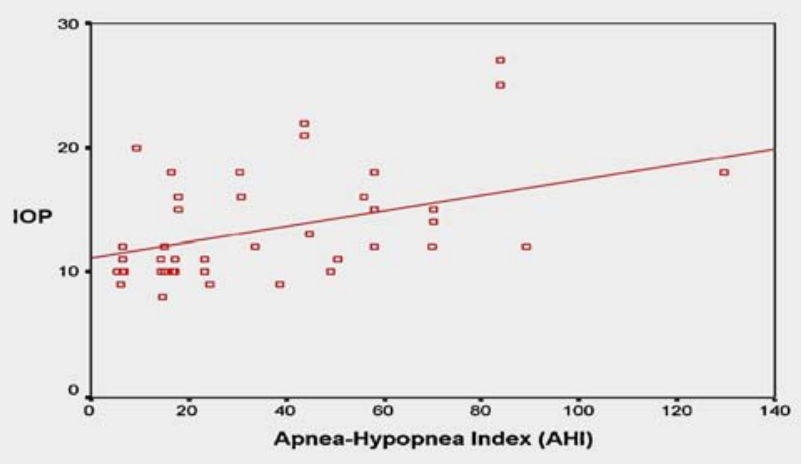

Fig. 4 The positive correlation between apnea-hypopnea index (AHI) and intraocular pressure (IOP) in the patient group is statistically significant $(r=0.426, p=0.001)$ 
nia, thereby leading to papilledema and increasing the risk of visual loss [25]. Since intracranial pressure increase in these patients is of intermittent character, cerebrospinal fluid pressure may be normal. In our group of patients, visual field defects were detected in ten patients despite normal ophthalmological examination. This may be due to optic nerve damage caused by cerebral ischemia and intermittent intracranial pressure increase in such patients.

Low diastolic pressure and systemic hypertension are reported to be strongly associated with glaucoma $[4,6,25$, 26]. Some authors suggested that physiological nocturnal hypotension, in the presence of other vascular risk factors, can bring the optic nerve head circulation under the critical levels and thus play a role in the pathogenesis of anterior ischemic neuropathy and glaucoma $[1,10,16,28]$.

The pathogenesis of LTG is not clear; however, optic nerve head hypoperfusion has been suggested as the cause [30]. Hayreh stated that many systemic and ocular paralyses occur at nighttime and may be realized when the patients awaken early in the morning [13]. Furthermore, Hayreh [13] and Meyer [19] suggested that nocturnal hypotension might play a role in the pathogenesis of LTG.

In conclusion, in our group of patients with OSAS, a high prevalence was found $(12.9 \%=4$ glaucoma patients of 31 OSAS patients) and it is interesting to note that all four of the glaucoma patients were in the severe OSAS group. The positive correlation detected between OARI and MD, and also between CRARI and MD as well as LV, suggests that visual field defects may be due to optic nerve perfusion defects and that these field defects also increase as the RI increases. The presence and progression of glaucoma should be investigated particularly in patients with severe OSAS in the long-term follow-up, and changes in retinal nerve fiber layer thickness and ocular Doppler ultrasonographic findings should also be monitored in such patients.

Acknowledgement The authors wish to thank Professor E. Mirza for his valuable contribution in editing the paper.

\section{References}

1. Arimoto T, Toratani A, Ito K, Iwasaki Y, Nakamura T, Nakagawa M (1995) Relationship between sleep stage and blood pressure variability during apnea in patients with sleep apnea syndrome. Nihon Kyobu Shikkan Gakkai Zasshi 33:917-923

2. Bucci FA, Krohel GB (1986) Optic nerve swelling secondary to the obstructive sleep apnea syndrome. Am J Ophthalmol 105:428-430

3. Culbertson WW, Ostler HB (1981) The floppy eyelid syndrome. Am J Ophthalmol 92:568-575

4. Dielemans I, Vidgerling JR, Algara D, Hofman A, Grobbee DE, Jong PT (1995) Primary open-angle glaucoma, intraocular pressure and systemic blood pressure in the general elderly population. The Rotterdam Study. Ophthalmology 102:54-60

5. Douglass AB, Bornstein R, Nino-Murcia G, Keenan S, Miles L, Zarcona VP Jr, Guilleminault C, Dement WC (1994) The Sleep
Disorders Questionnaire. I: creation and multivariate structure of SDQ. Sleep 17:160-167

6. Drance SM, Schulzer M, Thomas B, Douglas GR (1981) Multivariate analysis in glaucoma. Use of discriminant analysis in predicting glaucomatous visual field damage. Arch Ophthalmol 99:1019-1022

7. Fincher RME, Borger HE, Chaudhary BA (1986) Sleep apnea and optic disc swelling. Pak J Ophthalmol 2:13-15

8. Geyer O, Cohen N, Segev E, Rath EZ, Melamud L, Peled R, Lavie P (2003) The prevalence of glaucoma in patients with sleep apnea syndrome: same as in the general population. Am J Ophthalmol 136:1093-1096

9. Girkin CA, McGwin G Jr, McNeal SF, Owsley C (2006) Is there an association between pre-existing sleep apnea and the development of glaucoma? Br J Ophthalmol 90:679-681

10. Graham SL, Drance SM, Wijsman K, Douglas GR, Mikelberg FS (1995) Ambulatory blood pressure monitoring in glaucoma. Ophthalmology 102:61-69

11. Guilleminault C, van den Hoed J, Mitler M (1978) Clinical overview of the sleep apnea syndromes. In: Guilleminault C, Dement W (eds) Sleep apnea syndromes. Liss, New York, pp 1-12

12. Guilleminault C (1994) Clinical features and evaluation of obstructive sleep apnea. In: Karger MH, Roth T, Dement WC (eds) Principles and practice of sleep medicine. Saunders, London, pp 667-677

13. Hayreh SS, Zimmerman MB, Podhjasky P, Alward WL (1994) Nocturnal arterial hypotension and its role in optic nerve head and ocular ischemic disorders. Am J Ophthalmol 117:603-624

14. Hayreh SS (1996) Acute ischemia disorders of the optic nerve: pathogenesis, clinical manifestations and management. Ophthalmol Clin North Am 9:407-442

15. Kargi SH, Altin R, Koksal M, Kart L, Cinar F, Ugurbas SH, Ayoglu F (2005) Retinal nerve fibre layer measurements are reduced in patients with obstructive sleep apnea syndrome. Eye 19:575-579

16. Leroy M, Van Surell C, Pilliere R, Hagenmuller MP, Aegerter P, Raffestin B, Foucher A (1996) Short-term variability of blood pressure during sleep in snorers with or without apnea. Hypertension 28:937-943

17. Marcus DM, Costarides AP, Gokhale P, Papastergiou G, Miller JJ, Johnson MH, Chaudhary BA (2001) Sleep disorders: a risk factor for normal-tension glaucoma? J Glaucoma 10:177-183

18. McNab AA (1997) Floppy eyelid syndrome and obstructive sleep apnea. Ophthal Plast Reconstr Surg 13:98-114

19. Meyer JH, Brandi-Dohrn JB, Funk J (1996) Twenty four hour blood pressure monitoring in normal tension glaucoma. $\mathrm{Br} \mathrm{J}$ Ophthalmol 80:864-867

20. Mojon DS, Mathis J, Zulauf M, Koerner F, Hess CW (1998) Optic neuropathy associated with sleep apnea syndrome. Ophthalmology 105:874-877

21. Mojon DS, Hess CW, Goldblum D, Fleischhauer J, Koerner F, Bassetti C, Mathis J (1999) High prevalence of glaucoma in patients with sleep apnea syndrome. Ophthalmology 106:10091012

22. Mojon DS, Goldblum D, Fleischhauer J, Chiou AGY, Frueh BE, Hess CW, Gugger M, Bassetti C, Boehnke M, Mathis J (1999) Eyelid, conjunctival and corneal finding in sleep apnea syndrome. Ophthalmology 106:1182-1185

23. Mojon DS, Hess CW, Goldblum D, Boehnke M, Koerner F, Gugger M, Bassetti C, Mathis J (2002) Normal-tension glaucoma is associated with sleep apnea syndrome. Ophthalmologica 216:180-184

24. Onen SH, Mouriaux F, Berramdane L, Dascotte JC, Kulik JF, Rouland JF (2000) High prevalence of sleep-disordered breathing in patients with primary open-angle glaucoma. Acta Ophthalmol Scand 78:638-641 
25. Purvin VA, Kawasaki A, Yee RD (2000) Papilledema and obstructive sleep apnea syndrome. Arch Ophthalmol 118:16261630

26. Richler M, Werner EB, Thomas D (1982) Risk factors for progression of visual field defect in medically treated patients with glaucoma. Can J Ophthalmol 17:245-248

27. Robert PY, Adenis JP, Tapie P, Melloni B (1997) Eyelid hyperlaxity and obstructive sleep apnea syndrome. Eur J Ophthalmol 7:211-215
28. Shepard JW (1985) Gas exchange and hemodynamics during sleep. Med Clin North Am 69:1243-1264

29. Tsang CS, Chong SL, Ho CK, Li MF (2006) Moderate to severe obstructive sleep apnoea patients is associated with a higher incidence of visual field defect. Eye 20:38-42

30. Wellington DP, Johnstone MA (1994) Normal-tension glaucoma (low tension glaucoma). In: Albert DM, Jakobiec FA (eds) Principles and practice of ophthalmology. Saunders, Philadelphia, pp 1350-1365 